\title{
Morphological and immunohistochemical identification of epithelial-to-mesenchymal transition in clinical prostate cancer
}

\author{
Kimberley Kolijn ${ }^{1}$, Esther I. Verhoef ${ }^{1}$ and Geert J.L.H. van Leenders ${ }^{1}$ \\ ${ }^{1}$ Department of Pathology, Erasmus Medical Centre, Rotterdam, The Netherlands \\ Correspondence to: Kimberley Kolijn, email: k.kolijn@erasmusmc.nl \\ Keywords: epithelial-to-mesenchymal transition, ill-defined, N-cadherin, prostate cancer \\ Received: March 06, $2015 \quad$ Accepted: May 02, $2015 \quad$ Published: May 19, 2015
}

This is an open-access article distributed under the terms of the Creative Commons Attribution License, which permits unrestricted use, distribution, and reproduction in any medium, provided the original author and source are credited.

\section{ABSTRACT}

Epithelial-to-mesenchymal transition (EMT) is a process known to be associated with aggressive tumor behavior, metastasis and treatment resistance. It is characterized by coincidental upregulation of mesenchymal markers such as vimentin, fibronectin and $\mathrm{N}$-cadherin concurrent with $\mathrm{E}$-cadherin downregulation. Studies on EMT are generally performed in cell lines and mouse models, while the histopathological and phenotypical properties in clinical prostate cancer (PCa) are still unclear.

The objective of this study was to identify EMT in PCa patients. We demonstrated that $\mathbf{N}$-cadherin, vimentin and fibronectin were generally not co-expressed in corresponding tumor regions. Immunofluorescent double stainings confirmed that co-expression of mesenchymal markers was uncommon, as we found no prostate cancer cells that co-expressed $\mathrm{N}$-cadherin with fibronectin and only rare $(<1 \%)$ cells that co-expressed $\mathrm{N}$-cadherin with vimentin. Downregulation of E-cadherin was demonstrated in all $\mathrm{N}$-cadherin positive tumor cells, but not in vimentin or fibronectin positive tumor cells. We further analyzed $\mathrm{N}$-cadherin expression in morphologically distinct PCa growth patterns in a radical prostatectomy cohort $(n=77)$ and found that $\mathbf{N}$-cadherin is preferentially expressed in ill-defined Gleason grade 4 PCa. In conclusion, we demonstrate that $\mathrm{N}$-cadherin is the most reliable marker for EMT in clinical PCa and is preferentially expressed in ill-defined Gleason grade 4 growth pattern.

\section{INTRODUCTION}

The grade of differentiation in clinical $\mathrm{PCa}$ according to the modified Gleason scoring system is one of the most important predictive factors for disease behavior and therapeutic decision-making [1-3]. The Gleason grading system is solely based on architectural tumor growth patterns. While Gleason grade 1-3 PCa is composed of well-delineated malignant glands, various growth patterns classify as Gleason grade 4, such as illdefined, fused, glomeruloid and cribriform (Figure 1) [13]. Despite the widespread application of Gleason grading in clinical practice, little is known on the molecular background of specific Gleason grade growth patterns.

Understanding the molecular-biological processes by which tumor cells invade surrounding tissues and metastasize to distant sites, is an ongoing challenge in cancer research, as metastasis is the major cause of death for cancer patients. Metastasis requires cells to loose cellular connections and become migratory, which can be driven by the process of EMT [4]. Expression of E-cadherin (cadherin-1) is the keystone of epithelial cell state and is downregulated during EMT [4]. In many carcinomas including PCa, EMT is associated with invasive and aggressive behavior, metastasis to distant locations and treatment resistance [5-11]. Especially the shift from E-cadherin to N-cadherin (cadherin-2) expression correlates with cancer progression and metastasis [12-17].

While EMT in PCa has mainly been studied in cell line models, the morphological and phenotypic substrate of EMT in PCa patients is still unclear. In colon carcinoma, cancer cells undergoing EMT are characterized by spindleshaped morphology similar to in vitro studies [18]. In 
conventional clinical PCa, however, spindle-shaped tumor cells are not observed and thus the morphological substrate of EMT is still unclear in these tumors. The aim of this study was to investigate the morphology and location of EMT in clinical PCa. We demonstrate for the first time that EMT in $\mathrm{PCa}$ is characterized by $\mathrm{N}$-cadherin expression in morphologically ill-defined Gleason grade 4 PCa glands.

\section{RESULTS}

\section{EMT marker expression in benign and malignant prostate epithelium}

While EMT in cell culture models is characterized by simultaneous up- and downregulation of markers such as vimentin, N-cadherin and E-cadherin, it is not known whether synchronous expression also occurs within cell populations undergoing EMT in clinical PCa. First, we studied the expression of EMT markers vimentin, fibronectin, $\mathrm{N}$-cadherin and E-cadherin in a set of 23 radical prostatectomy (RP) specimens to determine which marker is most representative for EMT in clinical specimens and whether EMT markers were co-expressed within the same tumor areas. The clinicopathologic features of the cohort (primary set) are shown in Table 1.

Cytoplasmic vimentin was abundantly, although not homogeneously, expressed in normal fibromuscular prostate stroma of all patients, as well as in sporadic benign luminal epithelial cells of patients $(22 / 23,96 \%)$ (Table 2). In benign epithelium, only one case $(1 / 23$, $4 \%$ ) demonstrated complete absence of vimentin expression. Vimentin expression in benign epithelium
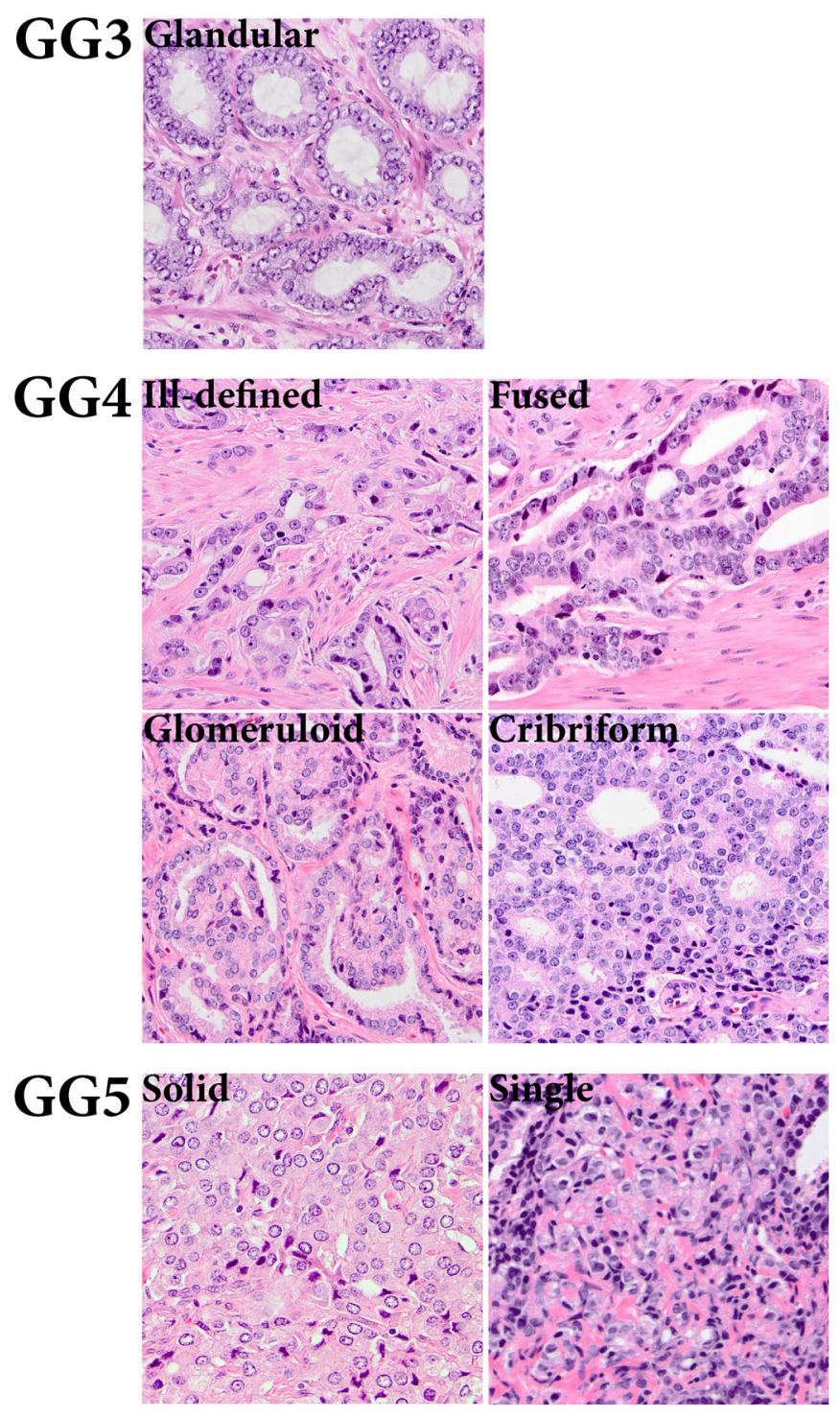

Figure 1: Gleason grade growth patterns of clinical prostate cancer. Gleason grade 3 (GG3) consists of well-delineated round to ellipsoid tumor glands. Gleason grade 4 (GG4) comprises the following growth patterns: ill-defined, fused, glomeruloid and cribriform. Gleason grade 5 (GG5) shows a solid tumor growth pattern or growth in single cells and cords (20x, original magnification). 
Table 1: Clinicopathologic features of the primary and extended RP cohorts.

\begin{tabular}{|c|c|c|c|}
\hline \multirow[b]{2}{*}{ Parameter } & & \multicolumn{2}{|c|}{ Mean (Median; range) or $\mathbf{n}(\%)$} \\
\hline & & Primary set $(n=23)$ & Extended set $(n=77)$ \\
\hline Age & & $66(67 ; 63-69)$ & $66(67 ; 51-79)$ \\
\hline PSA level (ng/mL) & & $22(15 ; 12-32)$ & $17(10 ; 2-97)$ \\
\hline \multirow[t]{6}{*}{ Gleason score } & 5 & $0(0 \%)$ & $1(1 \%)$ \\
\hline & 6 & $2(9 \%)$ & $12(16 \%)$ \\
\hline & $7(3+4)$ & $8(34 \%)$ & $33(43 \%)$ \\
\hline & $7(4+3)$ & $3(13 \%)$ & $14(18 \%)$ \\
\hline & 8 & $5(22 \%)$ & $9(12 \%)$ \\
\hline & 9 & $5(22 \%)$ & $8(10 \%)$ \\
\hline \multirow[t]{4}{*}{ pT stage (WHO 2009) } & pT2 & $0(0 \%)$ & $25(33 \%)$ \\
\hline & pT3a & $18(78 \%)$ & $41(53 \%)$ \\
\hline & pT3b & $5(22 \%)$ & $11(14 \%)$ \\
\hline & pT4 & $0(0 \%)$ & $0(0 \%)$ \\
\hline \multirow[t]{2}{*}{ Surgical margin } & Negative & $13(57 \%)$ & $49(64 \%)$ \\
\hline & Positive & $10(43 \%)$ & $28(36 \%)$ \\
\hline
\end{tabular}

PSA $=$ prostate specific antigen

Table 2. Immunohistochemical expression of vimentin, fibronectin and $\mathrm{N}$-cadherin in benign and malignant prostate epithelial cells in the primary RP cohort.

\begin{tabular}{l|l|c|c|c|c|}
\hline \multirow{2}{*}{ Marker } & \multirow{2}{*}{ Epithelium type } & \multicolumn{4}{|c|}{ Percentage of positive epithelial cells; n (\%) } \\
\cline { 3 - 6 } & & 0 & $<1 \%$ & $1-4 \%$ & $>4 \%-10 \%$ \\
\hline Vimentin & Benign $(\mathrm{n}=23)$ & $1(4 \%)$ & $18(78 \%)$ & $2(9 \%)$ & $2(9 \%)$ \\
\hline & PCa $(\mathrm{n}=23)$ & $14(61 \%)$ & $7(30 \%)$ & $2(9 \%)$ & $0(0 \%)$ \\
\hline Fibronectin & Benign $(\mathrm{n}=23)$ & $1(4 \%)$ & $22(96 \%)$ & $0(0 \%)$ & $0(0 \%)$ \\
\hline & PCa $(\mathrm{n}=23)$ & $2(9 \%)$ & $19(82 \%)$ & $0(0 \%)$ & $2(9 \%)$ \\
\hline N-cadherin & Benign $(\mathrm{n}=23)$ & $11(48 \%)$ & $12(52 \%)$ & $0(0 \%)$ & $0(0 \%)$ \\
\hline & PCa $(\mathrm{n}=23)$ & $10(44 \%)$ & $9(39 \%)$ & $1(4 \%)$ & $3(13 \%)$ \\
\hline
\end{tabular}

$\mathrm{PCa}=$ prostate cancer

was positive in $<1 \%$ of luminal cells in the majority of patients $(18 / 23,78 \%)$, while expression in $1-4 \%$ or $>4 \%$ $-10 \%$ of luminal cells occurred in $2 / 23(9 \%)$ cases each. Vimentin expression was observed in 9/23 (39\%) PCa specimens (Table 2); 7 tumors showed expression in $<$ $1 \%$ of malignant cells (30\%) and 2 cases in between $1 \%$ and $4 \%$ of malignant cells $(9 \%)$. In most tumors $(14 / 23$; $61 \%$ ), however, no vimentin expression was observed. The percentage of vimentin positive cells in benign epithelium was significantly higher than in $\mathrm{PCa}(p<0.001)$.
Fibronectin was abundantly expressed in the cytoplasm of prostate stromal cells and in $<1 \%$ of benign luminal epithelial cells $(22 / 23,96 \%)$ (Table 2). In PCa tissues, expression of fibronectin occurred most frequently in $<1 \%$ of tumor cells $(19 / 23,82 \%)$, while 2 cases were entirely negative $(2 / 23,9 \%)$ or showed expression in $>$ $4 \%-10 \%$ of PCa cells $(2 / 23 ; 9 \%)$ (Table 2). Expression of fibronectin was not statistically different in benign and malignant prostate epithelium $(p=0.28)$.

$\mathrm{N}$-cadherin was expressed in all nerve fibers, which 
Table 3: Expression of N-cadherin in distinct PCa growth patterns in the extended RP cohort.

\begin{tabular}{|l|c|c|c|}
\hline Growth pattern & Frequency of & Presence of & $\begin{array}{l}\text { Median (mean; range) } \\
\text { N-cadherin expression in }\end{array}$ \\
& & expression & cases \\
\hline Gleason grade 3 & & & $1 \%(1 \% ; 1-5 \%)$ \\
\hline Glandular & $75(97 \%)$ & $21 / 75(28 \%)$ & $10 \%(23 \% ; 1-100 \%)$ \\
\hline Gleason grade 4 & & & $5 \%(7 \% ; 5-10 \%)$ \\
\hline Ill- defined & $70(91 \%)$ & $27 / 70(39 \%)$ & $6 \%(6 \% ; 1-10 \%)$ \\
\hline Fused & $50(65 \%)$ & $3 / 50(6 \%)$ & $2 \%(2 \% ; 1-2 \%)$ \\
\hline Cribriform & $29(28 \%)$ & $2 / 29(7 \%)$ & $5 \%(5 \% ; 5 \%)$ \\
\hline Glomeruloid & $10(13 \%)$ & $2 / 10(20 \%)$ & $0 \%$ \\
\hline Gleason grade 5 & & & \\
\hline Cords, single cells & $8(10 \%)$ & $2 / 8(25 \%)$ & \\
\hline Solid fields & $4(5 \%)$ & $0 / 4(0 \%)$ & \\
\hline
\end{tabular}

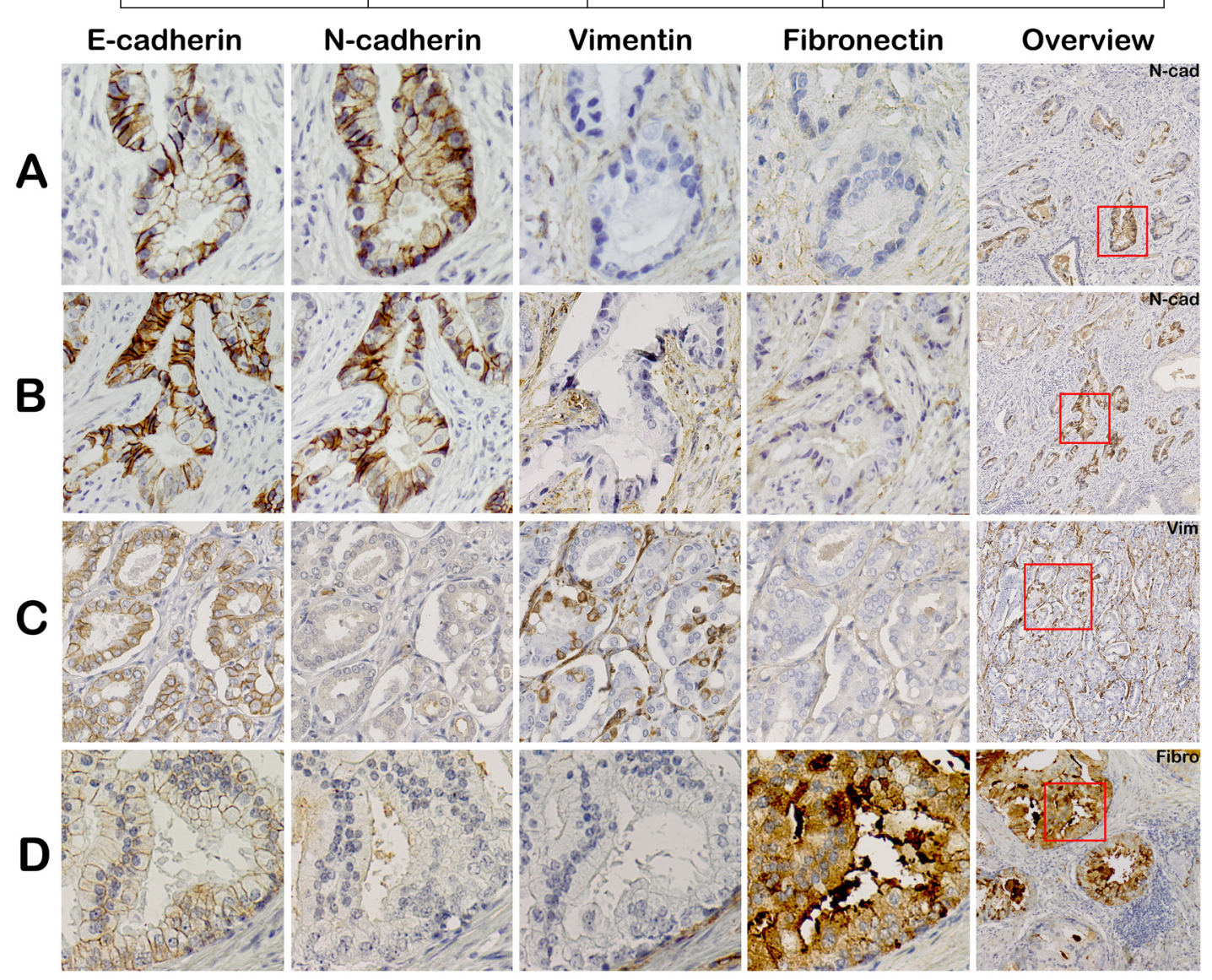

Figure 2: Mesenchymal EMT markers are not expressed in corresponding regions in clinical PCa. Consecutive slides were stained for EMT markers: E-cadherin, $\mathrm{N}$-cadherin, vimentin and fibronectin. Tumor areas positive for $\mathrm{N}$-cadherin were negative for vimentin and fibronectin (panel $\mathbf{A}$ and $\mathbf{B}$ ). Vimentin (panel $\mathbf{C}$ ) and fibronectin (panel D) positive tumor areas also did not co-express any of the other EMT markers (20x, original magnification). Overview slides demonstrate Gleason score $3+4=7$ (ill-defined; panel A, B), $3+4=7$ (fused; panel C) and 4+3 = 7 (cribriform; panel D). 
served as positive internal control in all cases. Expression in $<1 \%$ of benign luminal epithelial cells was present in $12 / 23$ samples $(52 \%)$, while the remaining cases were entirely negative $(11 / 23,48 \%)$ (Table 2$)$. In PCa, $\mathrm{N}$-cadherin expression was absent in 10 cases $(44 \%)$ or present in $<1 \%(9 / 23,39 \%), 1 \%-4 \%(1 / 23,4 \%)$ or $>$ $4 \%-10 \%(3 / 23,13 \%)$ of PCa cells (Table 2). Expression of $\mathrm{N}$-cadherin was statistically similar in benign and malignant prostate epithelium $(p=0.21)$, although high expression $(>1-10 \%)$ was exclusive to malignant epithelium. None of the EMT markers showed expression in more than $10 \%$ of benign or malignant epithelial cells.

Comparison of vimentin, fibronectin and $\mathrm{N}$-cadherin expression patterns in consecutive $\mathrm{PCa}$ sections did not reveal overlap of staining within corresponding areas (Figure 2). A hallmark event of EMT is downregulation of E-cadherin in epithelial cells. Areas with a complete loss of E-cadherin were not identified immunohistochemically in any case $(0 / 23)$, although focal variation in expression intensity was observed.

\section{Immunofluorescent co-expression analysis of} EMT markers

To verify that EMT markers vimentin, fibronectin and $\mathrm{N}$-cadherin were not expressed within the same cell population, we performed immunofluorescent coexpression analysis in PCa samples (Figure 3). Vimentin did not co-localize with fibronectin (Figure $3 \mathrm{~A}$ ). In only one patient, $<1 \%$ of $\mathrm{N}$-cadherin positive $\mathrm{PCa}$ cells were also positive for vimentin, while the vast majority of $\mathrm{N}$-cadherin positive cells were vimentin negative (Figure 3B). Co-localization of fibronectin and N-cadherin was not observed (Figure 3C). Therefore, vimentin, fibronectin and $\mathrm{N}$-cadherin were generally expressed in independent cell populations.

To determine which of the markers was most representative for EMT in clinical specimens, we performed immunofluorescent co-expression analysis with E-cadherin (Figure 4). Downregulation of E-cadherin was seen in all malignant cell clusters that expressed $\mathrm{N}$-cadherin, indicative of cadherin switching (Figure
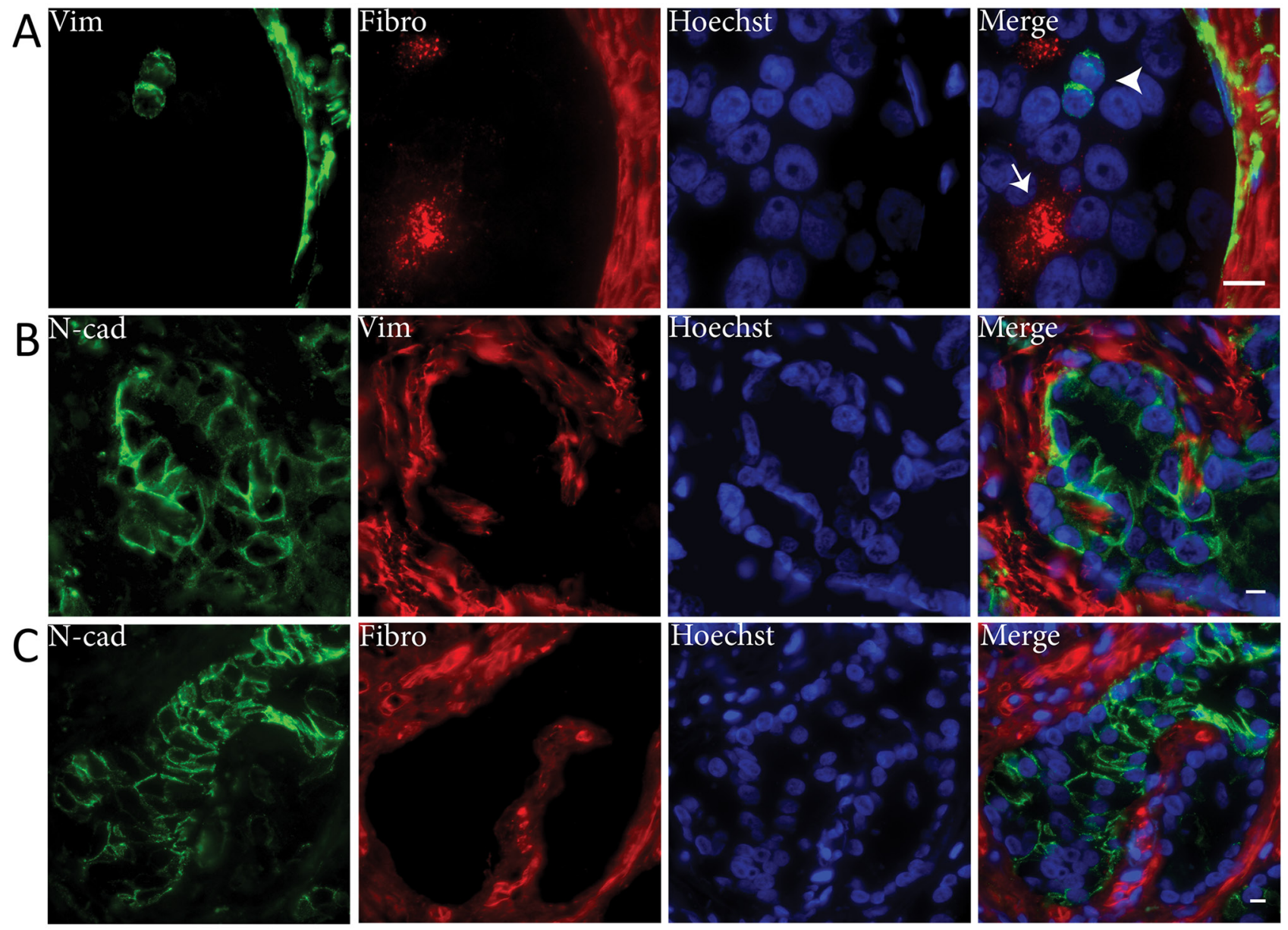

Figure 3: Mesenchymal EMT markers are not co-expressed in clinical PCa. Immunofluorescent double stainings demonstrated that vimentin (Vim) and fibronectin (Fibro) were not co-expressed (panel A). Vimentin positive PCa cells were fibronectin negative (arrowhead) and vice versa (arrow). N-cadherin (N-cad) was neither co-expressed with vimentin (panel B) or fibronectin (panel C). Original magnifications 100x (A) and 63x (B, C). Scale bar $=10 \mu \mathrm{m}$. 
4A) $[15,19]$. E-cadherin expression was high in the majority of vimentin positive PCa cells (Figure 4B). In a subpopulation (circa 10\%) of vimentin positive tumor cells, however, E-cadherin was slightly decreased (Figure 4C). None of the fibronectin positive PCa cells showed E-cadherin downregulation (Figure 4D). Since expression of $\mathrm{N}$-cadherin coincided with vast E-cadherin downregulation, $\mathrm{N}$-cadherin was considered the most reliable mesenchymal marker for EMT in clinical PCa.

\section{N-cadherin expression in clinical PCa}

EMT is preferentially occurring at the invasive front of various human cancers, such as oral squamous cell carcinoma and colorectal adenocarcinoma [20, 21]. In these tumor types, EMT is characterized by a spindlelike morphology of tumor cells and gain of mesenchymal markers. Spindle-shaped tumor cells, however, are not pathologically recognized in conventional PCa. To
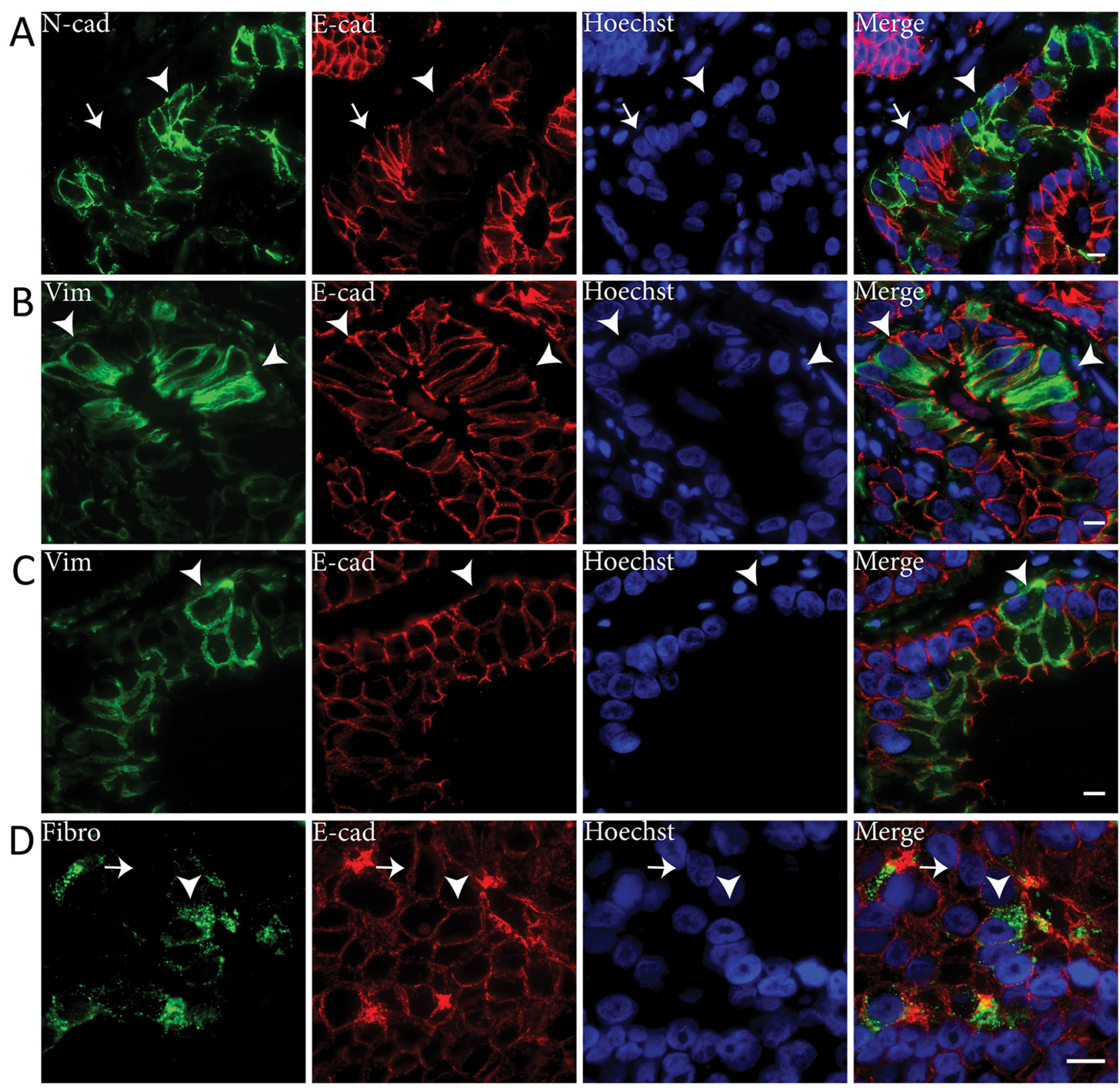

Figure 4: E-cadherin is downregulated in $\mathbf{N}$-cadherin positive tumor cell clusters in clinical PCa. Immunofluorescent double stainings showed E-cadherin (E-cad) downregulation in N-cadherin (N-cad) positive cell clusters (arrowhead) (panel A). N-cadherin negative cells demonstrated normal E-cadherin levels at the membrane (arrow). Vimentin (Vim) positive PCa cells generally expressed normal levels of E-cadherin (arrowheads) (panel B), although E-cadherin was downregulated in some vimentin positive cells (arrowheads) (panel C). Fibronectin (Fibro) positive PCa cells expressed similar E-cadherin levels (arrowhead) as fibronectin negative PCa cells (arrow) (panel D). Original magnifications 63x (A-C) and 100x (D). Scale bar $=10 \mu \mathrm{m}$. 
determine whether EMT as identified by N-cadherin expression was also related to a specific growth pattern in clinical $\mathrm{PCa}$, we quantified its expression in distinctive PCa growth patterns, as defined by the WHO 2009, in a set of 77 RP specimens (Figure 1) [1-3]. Expression of $\mathrm{N}$-cadherin occurred significantly more frequent in illdefined $(27 / 70,39 \%)$ than in fused $(3 / 50,6 \% ; p<0.001)$ or cribriform $(2 / 29,7 \% ; p=0.001)$ Gleason grade $4 \mathrm{PCa}$ (Table 3$)$. Although $\mathrm{N}$-cadherin expression occurred more often in ill-defined PCa $(27 / 70,39 \%)$ than in glandular Gleason grade $3(21 / 75,28 \% ; p=0.22)$, glomeruloid Gleason grade $4(2 / 10,20 \% ; p=0.31)$, solid fields $(0 / 4$, $0 \% ; p=0.29)$, cords and single cells $(2 / 8,25 \% ; p=$ $0.70)$ Gleason grade $5 \mathrm{PCa}$, the difference did not reach statistical significance. However, the overall percentage of $\mathrm{N}$-cadherin positive cells was significantly higher in ill-defined glands (median 10\%; range 1-100\%) than in Gleason grade 3 (median 1\%; range $1-5 \% ; p<0.001$ ) $\mathrm{PCa}$. Due to the low number of N-cadherin positive fused $(n=3)$, glomeruloid $(n=2)$, solid fields $(n=0)$, cords and single cells $(n=2)$ PCa growth patterns, statistical analysis was not performed in these cases. Expression of $\mathrm{N}$-cadherin was neither confined to the tumor boundary (invasive front) nor enriched in extra-prostatic (pT3) disease $(p=0.16)$.

\section{DISCUSSION}

EMT is an important biological process in embryogenesis, tissue homeostasis and tumor progression. It has been extensively studied in clinical colorectal cancer, where it is recognized as spindle-shaped tumor cells within desmoplastic stroma at the invasive front $[18,22-24]$. Studies on EMT in human prostate tissues generally encompass immunohistochemical analysis of single markers such as E-cadherin, N-cadherin, $\beta$-catenin, fibronectin, Slug, Snail, Twist, vimentin, ZEB1 and ZEB2 in relation to clinicopathologic features including death of disease and metastasis [12, 19, 25-30].

Various groups have pointed at the importance of EMT and N-cadherin expression for the progression of clinical PCa [7, 19, 25, 26, 31, 32]. Expression of $\mathrm{N}$-cadherin has been found in $0 \%$ up to $54 \%$ of $\mathrm{PCa}$ patients $[19,26,27]$. We found that $48 \%$ of $\mathrm{PCa}$ expressed N-cadherin, which is in line with other reports. Similar to previous studies, we have demonstrated that E-cadherin, a key EMT marker, was downregulated in $\mathrm{N}$-cadherin positive tumor cells, which is often referred to as cadherin switching $[12,19]$. In this study, we found that EMT as identified by $\mathrm{N}$-cadherin expression occurred preferentially in ill-defined PCa glands. Ill-defined PCa glands correspond to tumor glands with irregular outline and are considered a subtype of modified Gleason grade $4 \mathrm{PCa}$ [1]. While we also found expression in glandular Gleason 3, the median percentage of positive $\mathrm{N}$-cadherin cells was significantly lower as compared to ill-defined glands. As ill-defined modified Gleason grade $4 \mathrm{PCa}$ glands have an irregular contour and are strongly associated with immunohistochemical cadherin switching, they putatively represent the morphological substrate of EMT in clinical PCa.

Although $\mathrm{N}$-cadherin overexpression occurred preferentially in Gleason grade 4 ill-defined growth pattern, a significant number of ill-defined structures did not express $\mathrm{N}$-cadherin. It is possible that other cadherins such as OB-cadherin (cadherin-11) are upregulated in these prospective EMT regions $[33,34]$. EMT has also been implicated to play a role in therapy resistance $[6$, 35, 36]. Expression of mesenchymal markers including vimentin and fibronectin was increased and E-cadherin was decreased upon androgen deprivation in PCa patients $[6,35]$. Antibodies directing against N-cadherin inhibited tumor growth, metastasis and castration resistance of PCa cells in xenografted mice [36]. Since the stromal and inflammatory background in lymph node and bone metastasis is different from prostate stroma, in this study we specifically set out to investigate EMT in the context of its naive prostate background.

Although N-cadherin, vimentin and fibronectin are generally all considered as EMT markers, we found that they label independent cell populations in clinical specimens. Vimentin was regularly expressed both in benign epithelial glands and PCa with intact membranous E-cadherin, indicating vimentin expression does not necessarily confer mesenchymal properties to human prostate epithelial cells. Others have also demonstrated the abundant expression of vimentin in benign prostate epithelium and other epithelial cells including liver, kidney, vocal cords and breast [37-43]. Although fibronectin is an important EMT marker especially in in vitro studies, little is known about fibronectin expression in clinical cancers [44-49]. Expression and secretion of fibronectin allows cells to alter the extracellular matrix through the activation of matrix metalloproteinases and aid in migration $[50,51]$. We showed that fibronectin is expressed in only a small percentage of tumor cells that co-expressed E-cadherin, which argues against fibronectin as a marker for EMT in clinical specimens. Taken together, the role of vimentin and fibronectin as markers of EMT is less straightforward in clinical PCa than in vitro.

A novel approach in our study was the investigation of molecular markers in relation to specific growth patterns instead of more general Gleason grades. Gleason grade 4 PCa encompasses a heterogeneous group of tumor growth patterns such as ill-defined, fused, glomeruloid and cribriform. While the vast majority of clinical and biological studies regard Gleason grade $4 \mathrm{PCa}$ as a uniform tumor entity, we believe that discrimination of individual growth patterns adds new information to research analysis and facilitates comprehensive interpretation of research data. Recently, we and others have shown that cribriform growth in Gleason score $7 \mathrm{PCa}$ is a strong 
independent adverse parameter for distant metastasis and disease-specific death after RP $[52,53]$. Qian et al. demonstrated a copy number amplification of $c-M Y C$ in cribriform Gleason grade $4 \mathrm{PCa}$, but not in other Gleason grade 4 subtypes [54]. In this study, we demonstrate that $\mathrm{N}$-cadherin expression preferentially occurs in ill-defined Gleason grade $4 \mathrm{PCa}$, indicating that this specific growth pattern is representing biological EMT in clinical PCa. Therefore, taking individual Gleason grade 4 growth patterns into account adds value to the interpretation of both clinical and biological PCa studies.

A potential bias in our study is the fact that our RP specimens represent a selection of intermediate risk PCa. In our institute, RP is not the first choice of therapy for a large number of patients with limited Gleason score $6 \mathrm{PCa}$ on biopsy or with extensive high-risk disease. Since our population included a set of consecutive RP specimens not all growth patterns are represented equally. Although our study included the most prevalent PCa growth patterns, it cannot be excluded that the morphological substrate of EMT in pure Gleason grade 3 or less frequent Gleason grade 5 patterns is different than found in the current study. Finally, EMT refers to a dynamic process of cell transformation. Cadherin-switching is an important step in EMT, but it is unclear whether cadherin switching marks the entire or just a specific part of the dynamic EMT process.

In conclusion, we found that commonly used EMT markers vimentin, fibronectin and $\mathrm{N}$-cadherin are not co-expressed within the same cell populations in clinical PCa. Since E-cadherin is downregulated in tumor cells expressing N-cadherin but not vimentin or fibronectin, cadherin switching represents the best marker of EMT in PCa patients. N-cadherin expression occurred preferentially in ill-defined Gleason grade 4 $\mathrm{PCa}$, indicating that this specific growth pattern is the morphological substrate of EMT in clinical PCa.

\section{MATERIALS AND METHODS}

\section{Clinical specimens}

RP specimens were all retrieved from the archive of the department of pathology, Erasmus Medical Centre, Rotterdam, The Netherlands. All RP's had been performed in our institute between July 2010 and May 2013, prompted by histologically proven hormone-naïve $\mathrm{PCa}$ on diagnostic needle-biopsy. After receipt of RP specimens at the department of pathology, a transverse tissue slice was frozen in liquid nitrogen for research purposes. After thorough injection of 4\% neutralbuffered formalin to allow for fast and equal fixation of RP specimens, the prostate was pinned to a cardboard to avoid tissue retraction. After additional fixation overnight,
RP specimens were sliced transversally from apex to basis in $4 \mathrm{~mm}$ slices and completely embedded for pathologic analysis. At pathologic evaluation by a urogenital pathologist (GvL), modified Gleason score, extra-prostatic extension, seminal vesicle and bladder neck involvement, pT-stage (WHO 2009) and surgical margin status were all recorded. We included a primary set of $23 \mathrm{RP}$ specimens and an extended set of 77 RP specimens. The primary set $(N=23)$ was used to broadly analyse the expression of EMT-associated markers vimentin, fibronectin, E- and $\mathrm{N}$-cadherin, and determine whether respective markers were co-expressed in the same area. The extended set $(N=77)$ was an extension of the primary RP set $(N=$ $23)$ with 44 novel cases and was used to statistically relate the occurrence of EMT in well-described prostate cancer growth patterns. Use of RP specimens for research purposes was approved by the Erasmus MC Medical Ethics Committee (MEC-2011-295 and 296; August 25th, 2011) and is in accordance with the Helsinki Declaration of 1975 , as revised in 1983 .

\section{Immunohistochemistry}

Five $\mu \mathrm{m}$ slices were cut and mounted on aminoacetylsilane coated glass slides (Starfrost, Berlin, Germany). Slides were deparaffinized in xylene and rehydrated in decreasing ethanol steps. Endogenous peroxidase was blocked in $1 \%$ hydrogen peroxide in Phosphate Buffered Saline (PBS) for 20 min. Antigen retrieval was performed with TRIS (hydroxymethyl) aminomethane-EDTA (pH 9.0, Klinipath, Duiven, The Netherlands) in a microwave (MicroMed T/T Mega, Milestone, Sorisole, Italy) for $15 \mathrm{~min}$. Slides were incubated overnight at $4^{\circ} \mathrm{C}$ with primary antibodies targeting N-cadherin (1:50, clone 6G11, Dako, Glostrup, Denmark), vimentin (1:500, clone Vim3B4, Dako, Glostrup, Denmark), fibronectin (1:500, ab2413, Abcam, Cambridge, U.K.) or E-cadherin (1:200, clone NCH-38, Dako, Glostrup, Denmark) diluted in phosphate-buffered normal antibody diluent (Immunologic, Duiven, The Netherlands). The specificity of all antibodies had been verified using Western blot analysis (data not shown). Secondary antibodies were incubated for $30 \mathrm{~min}$. at room temperature and chromogenic visualization was performed with the EnVision Dako kit (Dako, Glostrup, Denmark). Slides were counterstained with haematoxylin, washed, dehydrated, cleared in xylene and mounted in Entellan ${ }^{\circledR}$ new (Merck Millipore, Billerica, U.S.A.). All immunohistochemical stainings included negative controls by omitting the primary antibody.

\section{Immunohistochemical analysis}

Immunohistochemical expression analysis was performed on consecutive PCa tissue sections of a 
primary set of $23 \mathrm{RP}$ specimens and an extended set of 77 RP's. The primary set was used to determine general expression patterns of EMT markers vimentin, fibronectin, N-cadherin and E-cadherin. In this set, expression of respective proteins was determined in benign prostate epithelium, $\mathrm{PCa}$ and intervening stroma. $\mathrm{N}$-cadherin was additionally scored in an extended set of RP specimens $(n=77)$ to examine its expression in specific PCa growth patterns [1-3]. The occurrence and relative percentage of individual $\mathrm{PCa}$ growth patterns were recorded in haematoxylin and eosin stained tissue slides by a urogenital pathologist $(\mathrm{GvL})$. The following growth patterns were distinguished: "glandular", defined as welldelineated round to ellipsoid PCa glands, corresponding to Gleason grade 3; "ill-defined", defined as PCa glands with an irregular outline; "fused", defined as more or less complex PCa structures often with slit-like lumina with the vast majority of cells being adjacent to surround stroma; "cribriform", defined as solid epithelial structures with punched-out lumina, with the majority of cells not contacting surrounding connective tissue; "glomeruloid", defined as intra-glandular epithelial proliferations resembling renal glomeruli, all corresponding to Gleason grade 4; "single cells", "cords" and "solid fields" all corresponding to Gleason grade 5 [1-3]. The percentage of N-cadherin positive tumor cells was semi-quantitatively estimated in all individual growth patterns present in one tissue section.

\section{Immunofluorescence}

Co-expression analysis of EMT markers was performed by immunofluorescent staining of 9 fresh frozen PCa samples. Sections of $5 \mu \mathrm{m}$ thick for were cut at a cryostat, fixed with $4 \%$ formaldehyde solution (Klinipath, Duiven, The Netherlands) for $20 \mathrm{~min}$. and permeabilised with $0.5 \%$ TritonX-100 in PBS for $10 \mathrm{~min}$. Slides were air-dried for one hour at room temperature, washed with PBS, and incubated with combinations of mouse anti-N-cadherin (1:25, clone 6G11, Dako, Glostrup, Denmark), rabbit anti-N-cadherin (1:75, clone D4R1H, Cell Signaling Technology, Danvers, U.S.A.), mouse anti-vimentin (1:100, clone Vim3B4, Dako, Glostrup, Denmark), rabbit anti-vimentin (1:100, clone D21H3, Cell Signaling Technology, Danvers, U.S.A.), mouse anti-E-cadherin (1:50, clone NCH-38, Dako, Glostrup, Denmark) or rabbit anti-fibronectin (1:200, ab2413, Abcam, Cambridge, U.K.) in 1\% bovine serum albumin (BSA) in PBS. The specificity of all antibodies had been verified using Western blot analysis and appropriate immunohistochemical controls (data not shown). After washing with PBS, slides were incubated with goat antimouse Ig labelled with Alexa 488 (1:200, Molecular Probes, Eugene, U.S.A.) combined with goat anti-rabbit Ig labelled with Alexa 594 (1:200, Molecular Probes, Eugene, U.S.A.), or goat anti-rabbit Ig labelled with Alexa
488 (1:200, Molecular Probes, Eugene, U.S.A.) combined with goat anti-mouse Ig labelled with Alexa 594 (1:200, Molecular Probes, Eugene, U.S.A.). Slides were mounted in Vectashield (Vector Laboratories, Peterborough, U.K.) containing Hoechst 34580 (1:4000, Life Technologies, Bleiswijk, The Netherlands) to visualize nuclei. Immunofluorescent tissue sections were analyzed using a confocal laser scanning microscope (Zeiss LSM 700, Carl Zeiss, Oberkochen, Germany) with ZEN 2012 imaging software (Carl Zeiss, Oberkochen, Germany).

\section{Statistics}

Comparison of EMT marker expression in benign prostate epithelium and $\mathrm{PCa}$ was analyzed using Pearson chi-square test. The frequency of $\mathrm{N}$-cadherin expression in separate $\mathrm{PCa}$ growth patterns was compared using the Fisher's exact test. The non-parametric Mann-Whitney $\mathrm{U}$ test was used to analyze the percentage of $\mathrm{N}$-cadherin positive tumor cells in individual growth patterns. A $\mathrm{p}$-value of $\leq 0.05$ was considered statistically significant. Statistical analyses were performed using IBM SPSS Statistics 21 (IBM Corp, Armonk, U.S.A.).

\section{CONFLICTS OF INTEREST}

The authors have no conflict of interest.

\section{GRANT SUPPORT}

This project was sponsored by the Dutch Cancer Society (EMCR2011-5006).

\section{REFERENCES}

1. Epstein JI, Allsbrook WC Jr, Amin MB, Egevad LL. The 2005 International Society of Urological Pathology (ISUP) Consensus Conference on Gleason Grading of Prostatic Carcinoma. Am J Surg Pathol. 2005; 29: 1228-1242.

2. Latour M, Amin MB, Billis A, Egevad L, Grignon DJ, Humphrey PA, Reuter VE, Sakr WA, Srigley JR, Wheeler TM, Yang XJ, Epstein JI. Grading of invasive cribriform carcinoma on prostate needle biopsy: an interobserver study among experts in genitourinary pathology. Am J Surg Pathol. 2008; 32: 1532-1539.

3. Lotan TL, Epstein JI. Gleason grading of prostatic adenocarcinoma with glomeruloid features on needle biopsy. Hum Pathol. 2009; 40: 471-477.

4. Hay ED. The mesenchymal cell, its role in the embryo, and the remarkable signaling mechanisms that create it. Dev Dyn. 2005; 233: 706-720.

5. Zhou YC, Liu JY, Li J, Zhang J, Xu YQ, Zhang HW, Qiu LB, Ding GR, Su XM, Mei-Shi; Guo GZ. Ionizing radiation promotes migration and invasion of cancer cells through 
transforming growth factor-beta-mediated epithelialmesenchymal transition. Int J Radiat Oncol Biol Phys. 2011; 81: 1530-1537.

6. Sun Y, Wang BE, Leong KG, Yue P, Li L, Jhunjhunwala S, Chen D, Seo K, Modrusan Z, Gao WQ, Settleman J, Johnson L. Androgen deprivation causes epithelialmesenchymal transition in the prostate: implications for androgen-deprivation therapy. Cancer Res. 2012; 72: 527536.

7. Perl AK, Wilgenbus P, Dahl U, Semb H, Christofori G. A causal role for E-cadherin in the transition from adenoma to carcinoma. Nature. 1998; 392: 190-193.

8. Josson S, Sharp S, Sung SY, Johnstone PA, Aneja R, Wang R, Gururajan M, Turner T, Chung LW, Yates C. Tumorstromal interactions influence radiation sensitivity in epithelial- versus mesenchymal-like prostate cancer cells. J Oncol. 2010; doi:10.1155/2010/232831.

9. Birchmeier W, Behrens J. Cadherin expression in carcinomas: role in the formation of cell junctions and the prevention of invasiveness. Biochim Biophys Acta. 1994; 1198: 11-26.

10. Jennbacken K, Tesan T, Wang W, Gustavsson H, Damber JE, Welen K. N-cadherin increases after androgen deprivation and is associated with metastasis in prostate cancer. Endocr Relat Cancer. 2010; 17: 469-479.

11. Marin-Aguilera M, Codony-Servat J, Reig O, Lozano JJ, Fernandez PL, Pereira MV, Jimenez N, Donovan M, Puig P, Mengual L, Bermudo R, Font A, Gallardo E, et al. Epithelial-to-mesenchymal transition mediates docetaxel resistance and high risk of relapse in prostate cancer. Mol Cancer Ther. 2014; 13: 1270-1284.

12. Gravdal K, Halvorsen OJ, Haukaas SA, Akslen LA. A switch from E-cadherin to $\mathrm{N}$-cadherin expression indicates epithelial to mesenchymal transition and is of strong and independent importance for the progress of prostate cancer. Clin Cancer Res. 2007; 13: 7003-7011.

13. Derycke LD, Bracke ME. N-cadherin in the spotlight of cell-cell adhesion, differentiation, embryogenesis, invasion and signalling. Int J Dev Biol. 2004; 48: 463-476.

14. Tran NL, Nagle RB, Cress AE, Heimark RL. N-Cadherin expression in human prostate carcinoma cell lines. An epithelial-mesenchymal transformation mediating adhesion with stromal cells. Am J Pathol. 1999; 155: 787-798.

15. Wheelock MJ, Shintani Y, Maeda M, Fukumoto Y, Johnson KR. Cadherin switching. J Cell Sci. 2008; 121: 727-735.

16. Nieman MT, Prudoff RS, Johnson KR, Wheelock MJ. $\mathrm{N}$-cadherin promotes motility in human breast cancer cells regardless of their E-cadherin expression. J Cell Biol. 1999; 147: 631-644.

17. Hazan RB, Phillips GR, Qiao RF, Norton L, Aaronson SA. Exogenous expression of $\mathrm{N}$-cadherin in breast cancer cells induces cell migration, invasion, and metastasis. J Cell Biol. 2000; 148: 779-790.

18. Brabletz T, Jung A, Reu S, Porzner M, Hlubek F, Kunz-
Schughart LA, Knuechel R, Kirchner T. Variable betacatenin expression in colorectal cancers indicates tumor progression driven by the tumor environment. Proc Natl Acad Sci U S A. 2001; 98: 10356-10361.

19. Tomita K, van Bokhoven A, van Leenders GJ, Ruijter ET, Jansen CF, Bussemakers MJ, Schalken JA. Cadherin switching in human prostate cancer progression. Cancer Res. 2000; 60: 3650-3654.

20. Smith A, Teknos TN, Pan Q. Epithelial to mesenchymal transition in head and neck squamous cell carcinoma. Oral Oncol. 2013; 49: 287-292.

21. Zhu QC, Gao RY, Wu W, Qin HL. Epithelial-mesenchymal transition and its role in the pathogenesis of colorectal cancer. Asian Pac J Cancer Prev. 2013; 14: 2689-2698.

22. Rees JR, Onwuegbusi BA, Save VE, Alderson D, Fitzgerald RC. In vivo and in vitro evidence for transforming growth factor-beta1-mediated epithelial to mesenchymal transition in esophageal adenocarcinoma. Cancer Res. 2006; 66: 9583-9590.

23. Guarino M, Rubino B, Ballabio G. The role of epithelialmesenchymal transition in cancer pathology. Pathology. 2007; 39: 305-318.

24. Brabletz T, Hlubek F, Spaderna S, Schmalhofer O, Hiendlmeyer E, Jung A, Kirchner T. Invasion and metastasis in colorectal cancer: epithelial-mesenchymal transition, mesenchymal-epithelial transition, stem cells and beta-catenin. Cells Tissues Organs. 2005; 179: 56-65.

25. Behnsawy HM, Miyake H, Harada K, Fujisawa M. Expression patterns of epithelial-mesenchymal transition markers in localized prostate cancer: significance in clinicopathological outcomes following radical prostatectomy. BJU Int. 2013; 111: 30-37.

26. Liu GL, Yang HJ, Liu T, Lin YZ. Expression and significance of E-cadherin, N-cadherin, transforming growth factor-beta1 and Twist in prostate cancer. Asian Pac J Trop Med. 2014; 7: 76-82.

27. Jaggi M, Nazemi T, Abrahams NA, Baker JJ, Galich A, Smith LM, Balaji KC. N-cadherin switching occurs in high Gleason grade prostate cancer. Prostate. 2006; 66: 193-199.

28. Lang SH, Hyde C, Reid IN, Hitchcock IS, Hart CA, Bryden AA, Villette, JM, Stower MJ, Maitland NJ. Enhanced expression of vimentin in motile prostate cell lines and in poorly differentiated and metastatic prostate carcinoma. Prostate. 2002; 52: 253-263.

29. Heatley M, Maxwell P, Whiteside C, Toner P. Vimentin and cytokeratin expression in nodular hyperplasia and carcinoma of the prostate. J Clin Pathol. 1995; 48: 10311034.

30. Steinestel K, Eder S, Schrader AJ, Steinestel J. Clinical significance of epithelial-mesenchymal transition. Clin Transl Med. 2014; 3: 17.

31. Graham TR, Zhau HE, Odero-Marah VA, Osunkoya AO, Kimbro KS, Tighiouart M, Liu T, Simons JW, O’Regan RM. Insulin-like growth factor-I-dependent up-regulation 
of ZEB1 drives epithelial-to-mesenchymal transition in human prostate cancer cells. Cancer Res. 2008; 68: 24792488 .

32. Kallakury BV, Sheehan CE, Winn-Deen E, Oliver J, Fisher HA, Kaufman RP Jr, Ross JS. Decreased expression of catenins (alpha and beta), p120 CTN, and E-cadherin cell adhesion proteins and E-cadherin gene promoter methylation in prostatic adenocarcinomas. Cancer. 2001; 92: 2786-2795.

33. Chu K, Cheng CJ, Ye X, Lee YC, Zurita AJ, Chen DT, Yu-Lee LY, Zhang S, Yeh ET, Hu MC, Logothetis CJ, Lin $\mathrm{SH}$. Cadherin-11 promotes the metastasis of prostate cancer cells to bone. Mol Cancer Res. 2008; 6: 1259-1267.

34. Huang CF, Lira C, Chu K, Bilen MA, Lee YC, Ye X, Kim SM, Ortiz A, Wu FL, Logothetis CJ, Yu-Lee LY, Lin SH. Cadherin-11 increases migration and invasion of prostate cancer cells and enhances their interaction with osteoblasts. Cancer Res. 2010; 70: 4580-4589.

35. Puhr M, Hoefer J, Schäfer G, Erb HH, Oh SJ, Klocker H, Heidegger I, Neuwirt H, Culig Z. Epithelial-tomesenchymal transition leads to docetaxel resistance in prostate cancer and is mediated by reduced expression of miR-200c and miR-205. Am J Pathol 2012; 181: 21882201.

36. Tanaka H, Kono E, Tran CP, Miyazaki H, Yamashiro J, Shimomura T, Fazli L, Wada R, Huang J, Vessella RL, An J, Horvath S, Gleave M et al. Monoclonal antibody targeting of $\mathrm{N}$-cadherin inhibits prostate cancer growth, metastasis and castration resistance. Nat Med 2010; 16: 1414-1420.

37. Wernert N, Seitz G, Achtstatter T. Immunohistochemical investigation of different cytokeratins and vimentin in the prostate from the fetal period up to adulthood and in prostate carcinoma. Pathol Res Pract. 1987; 182: 617-626.

38. Leong AS, Gilham P, Milios J. Cytokeratin and vimentin intermediate filament proteins in benign and neoplastic prostatic epithelium. Histopathology. 1988; 13: 435-442.

39. Fraga CH, True LD, Kirk D. Enhanced expression of the mesenchymal marker, vimentin, in hyperplastic versus normal human prostatic epithelium. J Urol. 1998; 159: 270274.

40. Li B, Zheng YW, Sano Y, Taniguchi H. Evidence for mesenchymal-epithelial transition associated with mouse hepatic stem cell differentiation. PLoS One. 2011; 6: e17092.

41. Kriz W, Kaissling B, Le Hir M. Epithelial-mesenchymal transition (EMT) in kidney fibrosis: fact or fantasy? J Clin Invest. 2011; 121: 468-474.

42. Mani SA, Guo W, Liao MJ, Eaton EN, Ayyanan A, Zhou AY, Brooks M, Reinhard F, Zhang CC, Shipitsin M, Campbell LL, Polyak K, Brisken C, Yang J, Weinberg RA. The epithelial-mesenchymal transition generates cells with properties of stem cells. Cell. 2008; 133: 704-715.

43. van der Velden LA, Schaafsma HE, Manni JJ, Link M,
Ruiter DJ, Ramaekers FC, Kuijpers W. Cytokeratin and vimentin expression in normal epithelium and benign lesions of the vocal cords. Acta Otolaryngol. 1996; 116: 325-331.

44. Park J, Schwarzbauer JE. Mammary epithelial cell interactions with fibronectin stimulate epithelialmesenchymal transition. Oncogene. 2014; 33: 1649-1657.

45. Albrecht M, Renneberg H, Wennemuth G, Moschler O, Janssen M, Aumuller G, Konrad L. Fibronectin in human prostatic cells in vivo and in vitro: expression, distribution, and pathological significance. Histochem Cell Biol. 1999; 112: 51-61.

46. Fernandez-Garcia B, Eiro N, Marin L, GonzalezReyes S, Gonzalez LO, Lamelas ML, Vizoso FJ. Expression and prognostic significance of fibronectin and matrix metalloproteases in breast cancer metastasis. Histopathology. 2014; 64: 512-522.

47. Han S, Khuri FR, Roman J. Fibronectin stimulates nonsmall cell lung carcinoma cell growth through activation of Akt/mammalian target of rapamycin/S6 kinase and inactivation of LKB1/AMP-activated protein kinase signal pathways. Cancer Res. 2006; 66: 315-323.

48. Yang Z, Zhang X, Gang H, Li X, Li Z, Wang T, Han J, Luo $\mathrm{T}$, Wen $\mathrm{F}, \mathrm{Wu} \mathrm{X}$. Up-regulation of gastric cancer cell invasion by Twist is accompanied by $\mathrm{N}$-cadherin and fibronectin expression. Biochem Biophys Res Commun. 2007; 358: 925-930.

49. Saito N, Nishimura H, Kameoka S. Clinical significance of fibronectin expression in colorectal cancer. Mol Med Rep. 2008; 1: 77-81.

50. Singh P, Carraher C, Schwarzbauer JE. Assembly of fibronectin extracellular matrix. Annu Rev Cell Dev Biol. 2010; 26: 397-419.

51. Moroz A, Delella FK, Lacorte LM, Deffune E, Felisbino SL. Fibronectin induces MMP2 expression in human prostate cancer cells. Biochem Biophys Res Commun. 2013; 430: 1319-1321.

52. Kweldam CF, Wildhagen MF, Steyerberg EW, Bangma $\mathrm{CH}$, van der Kwast $\mathrm{TH}$, van Leenders GJ. Cribriform growth is highly predictive for postoperative metastasis and disease-specific death in Gleason score 7 prostate cancer. Mod Pathol. 2014; 28: 457-464.

53. Dong F, Yang P, Wang C, Wu S, Xiao Y, McDougal WS, Young RH, Wu CL. Architectural heterogeneity and cribriform pattern predict adverse clinical outcome for Gleason grade 4 prostatic adenocarcinoma. Am J Surg Pathol. 2013; 37: 1855-1861.

54. Qian J, Jenkins RB, Bostwick DG. Detection of chromosomal anomalies and c-myc gene amplification in the cribriform pattern of prostatic intraepithelial neoplasia and carcinoma by fluorescence in situ hybridization. Mod Pathol. 1997; 10: 1113-1119. 